\title{
Penguatan identitas lokal dan penolakan vigilantisme atas nama agama
}

\author{
Strengthening local identity and rejection of vigilantism \\ in the name of religion
}

\author{
Manggala Ismanto \\ Program Studi Antropologi, Fakultas Ilmu Budaya, Universitas Brawijaya \\ Jalan Veteran No. 1 Malang, Jawa Timur 65145 \\ E-mail: manggala@ub.ac.id
}

\begin{abstract}
After the reformation, the strengthening of local identity has sprung up in several regions in Indonesia. The movement produced the revitalization of adat. These movements underlining the effort from communities which affiliated with a particular ethnic identity to gain claims of management of the natural and political-economic resources in their region. Contestation between the indigenous Dayak community and "Front Pembela Islam" (FPI) that occurred in Palangkaraya was a phenomenon that shows how indigenous people were able to assert its right to manage security and morality in their own society. The discourse of FPI's establishment which often associated with vigilantism brought resistance and the refusal from Dayak community in Central Kalimantan. Through demonstrations, DAD and the indigenous Dayak community was able to exclude FPI from Palangkaraya. Thus, this research aims to analyze (1) the history of ethnic and religious identity movements in Indonesia after the reformation and (2) how the contestation between indigenous Dayak community and FPI occurred in the local context according to identity recognition and legitimation. This research used qualitative approach; data gathered through field observation and unstrucutred interviews. The research concludes that there is an awareness in the community to negotiate their position as an opposition to the occurence of a group with particular ideology, which has become the research highlight. This was proven by the case in Palangkaraya that vigilantism on the name of religion is not supposed to be maintain because it violates the right of other group.
\end{abstract}

Keywords: identity politics, citizenship, contestation, vigilantism

\begin{abstract}
Abstrak
Setelah reformasi bergulir, penguatan identitas lokal bermunculan di beberapa wilayah di Indonesia dan menghasilkan 'revitalization of adat'. Gerakan ini menegaskan adanya upaya masyarakat yang berafiliasi dengan identitas etnis tertentu untuk mendapatkan klaim atas pengelolaan sumber daya dan politik-ekonomi di daerahnya. Kontestasi antara masyarakat adat Dayak dan FPI yang terjadi di Palangkaraya merupakan fenomena yang menunjukkan bagaimana 'masyarakat adat' mampu menegaskan haknya untuk mengelola keamanan dan moral masyarakatnya sendiri. Wacana pendirian FPI yang sering dikaitkan dengan vigilantism memicu resistensi dan penolakan dari masyarakat Dayak di Kalimantan Tengah. Melalui aksi demonstrasi, DAD dan masyarakat Dayak mampu mengeksklusi FPI dari Palangkaraya. Penelitian ini bertujuan untuk menjelaskan fenomena tersebut dengan menganalisa (1) sejarah gerakan identitas etnis dan agama di Indonesia pasca reformasi dan (2) bagaimana kontestasi antara masyarakat adat Dayak dan FPI terjadi dalam konteks lokal terkait dengan pengakuan dan legitimasi identitas. Penelitian ini menggunakan pendekatan kualitatif dengan metode pengumpulan data observasi atas fenomena yang terjadi di lapangan dan wawancara tidak terstruktur. Penelitian ini menyimpulkan bahwa terdapat kesadaran pada kelompok masyarakat agar dapat menegosiasikan posisinya untuk menolak kehadiran sebuah kelompok yang membawa ideologi tertentu, yang merupakan poin penting penelitian. Dibuktikan dengan kasus di Palangkaraya bahwa tindakan vigilantisme atas nama agama tidak bisa dilanggengkan, karena menodai hak kelompok lain yang berbeda.
\end{abstract}

Kata kunci: politik identitas,citizenship, kontestasi, vigilantism

\section{Pendahuluan}

Politik pembedaan atau "politic of difference" menjadi salah satu ciri dari kewarganegaraan di Indonesia pasca rezim soeharto lengser. Seperti yang dikatakan oleh Holston \& Appadurai (1996), bahwa konsep kewarganegaraan yang dianggap bersifat netral selalu menghadapi tantangan dalam konteks masyarakat yang multi-identitas. Kelompok-kelompok yang memiliki latar belakang sejarah dan karakteristik yang berbeda memaknai ulang hubungan antara hak dan kewajiban sebagai warga negara. Perbedaan ini yang mendasari bahwa setiap kelompok berupaya untuk mendapatkan 
'perlakuan' yang berbeda dan untuk dihargai keberadaannya. Beberapa kelompok identitas termasuk didalamnya adalah kelompok minoritas, kelompok orientasi seksual, ras, keagamaan maupun organisasi berdasarkan etnis. Masing-masing kelompok memiliki klaim dengan tujuan:

\begin{abstract}
"...demand different treatment on the basis of their inalienable right to retain and realize their unique qualities, contributions, and histories. Their core argument usually entails the claim they have been denied respect and opportunity because they are different. That difference in fact constitutes their authentic and original character, which they have every right to develop to full capacity" (Holston \& Appadurai 1996:194).
\end{abstract}

Tidak menuntup kemungkinan pertemuan dua kelompok dengan 'keunikan, kontribusi dan sejarah' yang berbeda akan menghasilkan kontestasi kepentingan. Munculnya lembaga-lembaga adat dan juga organisasi Islam menjadi gambaran suburnya politik perbedaan. Apa yang terjadi ketika dua kelompok yang mengusung hak atas perbedaan ini bertemu pada suatu konteks ruang dan waktu yang sama? Holston (1998:3) menyebutkan bahwa kemunculan insurgent citizenship bisa menimbulkan bentuk-bentuk-bentuk baru kekerasan dan ekslusi.

"...,the worldwide insurgence of democratic citizenships in recent decades has disrupted established formulas of rule and privilege in the most diverse societiees. The result is an entanglement of democracy with its counters, in which new kinds citizens arise to expand democratic citizenship and new forms of violence and exlusion simultaneosly erode it" (Holston 1998).

Pembahasan tentang revitalisasi adat dan kemunculan politik Islam yang muncul pasca reformasi telah dikaji beberapa peneliti. Davidson dan Hanley (2007) menjelaskan kemunculan politik identitas berbasis adat dan tradisi di beberapa wilayah di Indonesia pasca reformasi. Hal tersebut terjadi karena adanya desentralisasi kekuasaan dan penguatan identitas masyarakat lokal yang pernah direpresi pada pada rezim orde baru. Di sisi lain, terkait dengan politik Islam di Indonesia Abuza (2007), salah satunya kemunculan kelompok islam radikal juga bermula dari terbukanya kesempatan pada era reformasi untuk berkembangnya kelompok civil society yang beragam. Kajian-kajian tersebut melihat perkembangan serta kemunculan politik identitas di Indonesia pasca reformasi dengan fokus masing-masing yaitu adat maupun agama. Dalam penelitian ini saya ingin melihat bahwa kedua entitas tersebut ternyata bisa bertemu pada sebuah konteks ruang dan waktu dan menghasilkan kontestasi serta ekslusi yang dilakukan oleh satu pihak terhadap pihak lain.

Kemunculan politik pembeda serta bentuk-bentuk kekerasan serta ekslusi yang terbentuk dari 'insurgence of democratic citizenships' inilah yang menjadi perhatian pada artikel ini. Pertemuan dua kelompok yang masing-masing mengusung hak untuk mendapatkan pengakuan dan klaim terjadi pada konteks kontestasi antara komunitas adat serta organisasi Islam di Kalimantan Tengah. Masyarakat Dayak dengan identitas adatnya ingin meneguhkan posisi sebagai warga negara yang mendapatkan akses penuh terhadap sumberdaya maupun kontrol politik di tempat tinggalnya. Kelompok garis keras FPI (Front Pembela Islam), ingin melebarkan sayapnya dan menyebarkan ideologi Islam "memimpin manusia menuju kebajikan" di beberapa provinsi di Indonesia. Pertemuan keduanya menghasilkan bentuk-bentuk kekerasan dan juga ekslusi.

Siapa yang menjadi kelompok mayoritas dan minoritas seperti yang dinyatakan Kymlicka (1995) sebagai relasi bentuk kemunculan penguatan hak dari kelompok yang termarjinalkan dalam kasus ini cukup kabur. Masing-masing memegang prinsip politik perbedaan dengan menggugat klaim dan perlakuan yang berbeda atas dasar keunikan, kontribusi dan perbedaan historis. Pada artikel ini penulis ingin melihat bagaimana kedua kelompok tersebut muncul pada era reformasi dan bagaimana kontestasi yang terjadi ketika kedua kelompok itu bertemu pada konteks tertentu. 


\section{Metode Penelitian}

Dalam penelitian ini penulis menggunakan pendekatan kualitatif. Penelitian kualitatif meliputi proses pengumpulan yang bervariasi dari materi-materi empiris, termasuk didalamnya studi kasus, pengalaman pribadi, life story, wawancara, teks-teks, observasi maupun teks visual (Denzin \& Lincoln 2005). Dalam penelitian kualitatif peneliti diharapkan melakukan interpretasi terhadap fenomena yang dihadapi untuk mendapatkan pemahaman yang mendalam (Denzin \& Lincoln 2005). Untuk pengumpulan data kualitatif penulis mengumpulkan data yang bersifat primer dan sekunder. Untuk mengumpulkan data primer, penulis berada di kota Palangkaraya selama kurang lebih satu bulan. Penulis melakukan observasi atas fenomena yang terjadi di lapangan terkait dengan aksi demonstrasi menolak FPI di Palangkaraya. Saat observasi penulis mengamati bagaimana demonstrasi berlangsung, kegiatan apa saja yang terjadi, serta selain itu penulis juga melakukan wawancara tidak terstruktur kepada informan yang ikut dalam aksi demonstrasi.

Upaya untuk mengungkap lebih dalam fenomena tersebut, penulis melengkapi data primer dengan data sekunder. Penulis mengumpulkan informasi yang berasal dari kumpulan dokumentasi dan kajian terkait tema dan fenomena yang akan diteliti. Data tersebut diantaranya adalah buku referensi, jurnal, pemberitaan di media massa, maupun foto.

\section{Hasil dan Pembahasan}

\section{Revitalisasi adat dan politik identitas di Kalimantan Tengah}

Kata adat kembali berkumandang di Indonesia akhir-akhir ini terkait dengan banyak kemunculan lembaga atau institusi adat, kembalinya hukum adat, maupun lahirnya istilah putra daerah di beberapa kawasan. Adat sendiri memiliki definisi dan pengertian yang cukup beragam. Oleh karena itu penulis mencoba untuk mencari salah satu pengertian cukup mewakili apa yang dinyatakan sebagai adat. Dalam artikel ini, penulis sependapat dengan pengertian adat dalam konteks politik dari sudut pandang Davidson \& Hanley (2007). Mereka menjelaskan, secara abstrak, adat dalam konteks Indonesia bisa dinyatakan sebagai "a complex of rights and obligations which ties together three things -history, land and law".

Kemunculan adat memang tidak bisa dilepaskan dari perkembangan dan keadaan politik di Indonesia pasca keruntuhan orde baru pada tahun 1998. Lengsernya Presiden Soeharto kala itu menjadi momen besar yang mengakibatkan pergeseran kekuasaan politik yang sangat sentralistik dan otoriter menuju pada pembagian kekuatan politik pada ranah lokal. Kekuatan politik lokal inilah yang menginginkan adanya legitimasi baru atas kekuatannya melalui adat. Davidson \& Hanley (2007) membicarakan kemunculan istilah adat yang cukup menggaung pasca reformasi ini:

\footnotetext{
"Since the resignation of President Suharto in 1998 after almost a third of a century of authoritarian rule, communities and ethnic groups across Indonesia have publicly, vocally, and sometimes violently, demanded the right to implement elements of adat or hukum adat (customary law) in their home territories".
}

Adat sendiri tidak hanya digunakan untuk mengambil kekuasaan (politik) yang terbagi setelah rezim jatuh, tetapi juga sebagai upaya untuk mengakses kembali sumber daya (ekonomi). Sumber daya yang telah lama dikuasai oleh pemerintah pusat secara otoriter coba direbut kembali oleh masyarakat di daerah yang mulai otonom dengan memanfaatkan adat. Dengan menggunakan istilah revitalisasi adat, F. von Benda-Beckmann \& K. von Benda-Beckmann (2011) melihat bahwa, "the revitalization of adat is most discernible in the prominent rise of adat law, and political and economic claims are based on that law in order to carve out a greater role for adat leadership in village government and recognition of adat rights to natural resources". 
Terkait dengan adanya kesempatan untuk melepaskan diri dari kekangan rezim orde baru yang otoriter, penulis ingin melihat bagaimana adat menjadi kekuatan politis baru untuk mendapatkan kekuatan atau kekuasaan baik berbentuk materil maupun simbolik pada era reformasi. Davidson \& Hanley (2007) menjelaskan kemunculan beragam gerakan yang mengatasnamakan adat tersebut dengan istilah kebangkitan adat atau yang disebut sebagai adat revivalism. Muncul beberapa faktor yang menyebabkan kebangkitan adat di Indonesia bisa terjadi cukup masif di beberapa daerah. Salah satu penyebab adat bangkit adalah saat runtuhnya pemerintahan orde baru pada tahun 1999. Kegamangan yang muncul di awal era reformasi tentang siapa yang berkuasa di ranah lokal setelah jatuhnya Soeharto memicu kemunculan adat. Pada saat itulah adat digunakan sebagai, "both a means of redressing past injustice and a way of securing an advantageous position in the post-Suharto scramble for power in the regions" Davidson \& Hanley (2007).

Dalam konteks Kalimantan Tengah, revitalisasi atau kebangkitan adat juga menjadi salah satu isu yang muncul di era reformasi. Fenomena yang terjadi di Kalimantan Tengah adalah bentuk institusionalisasi adat yang didukung oleh kebijakan pemerintah. Dengan adanya kebijakan pemerintah daerah itulah muncul institusi atau lembaga adat bernama DAD (Dewan Adat Dayak) yang memiliki tujuan untuk menguatkan peran adat di Kalimantan Tengah. Selain itu pula, muncul organisasi bernamakan LMMDD-KT (Lembaga Musyawarah Masyarakat Dayak dan Daerah Kalimantan Tengah) dengan tujuan menguatkan peran politik putra daerah.

Salah satu bentuk lembaga adat yang sudah sejak lama ada di Kalimantan Tengah adalah "Kademangan". Kademangan merupakan salah satu bentuk organisasi yang bersifat sosial religius, yang memiliki fungsi sebagai wadah interaksi sosial masyarakat Dayak terkait dengan upacara adat dan agama. Kata kademangan itu sendiri berarti persekutuan orang yang hidup dalam satu wilayah tertentu dengan ciri khas masih memiliki ikatan sosial yang masih kental dan hidup bergantung pada alam (Diansyah 2011). Kademangan ini dipimpin oleh Damang atau pemangku adat yang memiliki peran sebagai pemimpin adat untuk menegakkan hukum adat Dayak di daerah tersebut. Lembaga ini merupakan lembaga adat yang memang sudah berumur panjang di Kalimantan Tengah, khususnya di daerah Palangkaraya. Salah satu bukti dari eksistensi kademangan ini adalah diselenggarakannya musyawarah perdamaian Tumbang Anoi pada tahun 1894 (Diansyah 2011).

Kebijakan secara legal formal yang pertama kali menegaskan kedudukan kademangan di Kalimantan berasal dari kebijakan kolonial Belanda. Pada saat itu diperlukan kantong-kantong kekuasaan yang dipimpin oleh penduduk lokal pada kawasan administrasi yang lebih kecil untuk mendukung kekuasaan Kolonial. Pada masa penjajahan, lembaga kademangan diatur dalam Besluiten van den Resident Zuider-en Oosterafdeeling van Boerneo yang dikeluarkan pada tanggal 28 Oktober 1938 Nomor 349/c 7-1 (Diansyah 2011:10). Kebijakan ini mengatur mengenai penunjukan dari kedemangan-kedemangan dalam onderafdeeling- onderafdeeling di wilayah tanah Dayak, dan selanjutnya pada masa itu disebut sebagai demang (Diansyah 2011:10). Peraturan Belanda yang diimplemetasikan pada tahun 1938 ini seperti membangkitkan lagi eksistensi lembaga kedemangan yang sempat surut. Tjilik Riwut (dalam Diansyah 2011) mengatakan bahwa Damang Kepala Adat yang dikukuhkan pemerintah Hindia Belanda pada tahun 1938 sebagai tindakan rehabilitasi sekaligus pengakuan terhadap adat istiadat leluhur orang Dayak.

Setelah reformasi, revitalisasi adat yang disahkan oleh pemerintah Kalimantan Tengah untuk pertama kali muncul untuk melegalkan kademangan yang eksistensinya secara sosial dan kultural di masyarakat telah diakui. Tepatnya pada tahun 1998 telah disahkan kebijakan daerah untuk memberi legalitas dan kekuatan bagi kedudukan damang. Peraturan tersebut tertuang dalam Peraturan Daerah Propinsi Daerah Tingkat I Kalimantan Tengah Nomor 14 Tahun 1998 tentang Kademangan di Propinsi Daerah Tingkat I Kalimantan Tengah. Dalam peraturan daerah tahun 1998 inilah definisi serta hak dan kewajiban dari kademangan dilegalkan secara hukum. Dalam peraturan ini apa yang disebut dengan kademangan adalah wilayah yang meliputi kecamatan atau lebih dari satu kecamatan yang dipimpin oleh damang kepala adat yang merupakan pimpinan adat yang dipilih atau diangkat berdasarkan hasil pemilihan dari beberapa desa atau kecamatan di wilayah kademangan tersebut. 
Setelah satu dasawarsa peraturan kademangan tahun 1998 ini diimplementasikan terjadi perubahan cukup signifikan terkait dengan kelembagaan adat di Kalimantan Tengah. Karena lembaga kademangan yang diatur sebelumnya dianggap kurang sesuai dengan perkembangan jaman di era otonomi daerah, pemerintah Kalimantan Tengah melakukan perubahan kebijakan dengan tujuan mendirikan institusi adat bernama Dewan Adat Dayak. Kelahiran institusi adat tersebut tertuang pada Peraturan Daerah No.18 tahun 2008 mengenai Kelembagaan Adat Dayak di Kalimantan Tengah.

Kademangan yang berdiri dan tumbuh secara organik di masyarakat Dayak secara turun temurun dianggap perlu diwadahi oleh kelembagaan Dayak yang lebih besar lagi. Disebutkan bahwa Kademangan perlu "dilestarikan, dikembangkan dan diberdayakan" untuk kepentingan masyarakat "dengan didukung dan dibantu [diatur dan diawasi] oleh kelembagaan adat Dayak lainnya, sehingga sesuai dengan perkembangan dan tuntutan kebutuhan daerah otonom dalam bingkai Negara Kesatuan Indonesia" (pasal 2 ayat 1). Tidak hanya itu, lembaga adat tersebut perlu juga diberi "kedudukan, kewenangan, tugas, fungsi, dan peran", yang nantinya dianggap mampu memenuhi kebutuhan daerah otonomi (pasal 2 ayat 2).

Selain adanya lembaga adat yang didukung oleh pemerintah, kemunculan organisasi bernama LMMDD-KT memberikan pengaruh pada bentuk politik identitas di Kalimantan Tengah. Lembaga yang didirikan pada 1993 oleh salah satu akademisi Dayak bernama Prof. K.M.A Usop ini memiliki visi untuk meningkatkan peran politik masyarakat Dayak di Kalimantan Tengah. Perjuangan untuk mendapatkan peran di ranah birokrasi terkait dengan tersingkirnya orang Dayak sebagai pemimpin pada masa orde baru. Seperti yang dinyatakan Malley (1999 dalam Klinken 2007) bahwa lembaga ini "berupaya untuk menekan [pemerintah pusat] Jakarta agar tidak memilih orang Jawa sebagai gubernur tetapi memilih putra daerah". Salah satu momen penting adalah ketika gubernur dari rezim orde baru Warsito Rasman telah habis masa kepempimpinannya pada Juli 1999, lembaga ini melakukan aksi protes untuk meminta agar orang Dayak mendapatkan kesempatan menjadi pemimpin di daerahnya (Klinken 2001).

Salah satu usaha untuk memberikan dorongan pada peran putra daerah, lembaga ini melaksanakan kongres di Kalimantan Tengah pada tahun1998. Momen ini menjadi penting karena saat itu otoritas rezim orde baru sedang mengalami guncangan. Pada kongres ini jargon yang diperkenalkan kepada masyarakat Kalimantan Tengah adalah 'masyarakat Dayak sebagai tuan rumah di daerahnya sendiri'. Pengaruh dari kongres ini pun terjadi di luar Kalimantan. Kongres serupa diadakan pada tahun 2000 di beberapa provinsi dengan mengangkat tema yang sama tentang penguatan politik identitas, seperti di Riau, Papua, dan Minahasa (Sulawesi Utara) (Klinken 2007). Lembaga bernapaskan identitas ini menurut Klinken (2007) diibaratkan seperti partai politik dengan ideologi putra daerah.

\begin{abstract}
LMMDD-KT was in reality a local political party whose nativist ideology was narrowly focused on control of the bureaucracy. It challenged the technocratic language of the New Order with an idiom of indigenous rights, and the New Order anti-political formalisms with populist mobilization. Yet its interest in oppositional agendas did not extend beyond indigenous rights to areas like anti-militarism, workers rights, land rights, the environment, gender equality or even the rule of law. In that sense it remained wedded to the elitism of the New Order.
\end{abstract}

Agenda politik lembaga ini adalah untuk memenangkan pemimpin Dayak sebagai gubernur pada pemilihan tahun 2000. Calon yang diusung oleh lembaga ini adalah pendirinya, yaitu Prof. Usop. Dengan memiliki cabang di setiap kecamatan di provinsi dan melakukan lobby politik LMMDDKT berupaya menguatkan pengaruh Dayak di birokrasi pemerintahan daerah, namun pada akhirnya calon yang diusung lembaga tersebut gagal dan dimenangkan oleh pesaing politiknya yaitu Asmawi Agani, putra daerah Dayak yang pernah menjabat sebagai Bupati Barito Selatan. Meskipun secara politik lembaga tersebut tidak mampu mendapatkan posisi pemimpin daerah, tetapi bisa dikatakan lembaga tersebut memiliki peran untuk menyuarakan isu tentang kepemimpinan putra daerah di Kalimantan Tengah Klinken (2007). 


\section{Front Pembela Islam: Pengontrol moral atau vigilantee?}

Pasca bergantinya rezim Soeharto pada tahun 1998 turut mempengaruhi kehadiran kelompokkelompok Islam di Indonesia. Menurut Abuza (2007:9) meningkatnya kekerasan politik pasca rezim Soeharto sering dikaitkan dengan munculnya politik Islam dan Islam radikal. Abuza mengatakan gerakan Politik Islam di Indonesia dikelompokkan menjadi beberapa kategori. Pertama adalah politik Islam, partai politik dan institusi nasional yang berafiliasi dengan Islam yang mendukung peran Islam yang lebih besar dalam kehidupan politik dan sosial. Kedua adalah Islam militan, berupa kelompok-kelompok radikal yang didukung oleh pihak yang berhubungan dengan konflik dengan intensitas rendah yang mendukung peran Islam di Indonesia dalam kehidupan sosial serta politik. Kemudian terorisme, organisasi militan radikal yang menggunakan taktik teroris untuk perubahan radikal secara politik dan sosial.

Pada bagian ini penulis akan memfokuskan pada kelompok Islam yang lahir saat itu identik dengan garis keras dan juga berperan pada aksi kekerasan di beberapa wilayah di Indonesia dengan dalih untuk menegakkan aturan (syariah) Islam. Islam garis keras menurut Wahid (2009:45) diidentikkan dengan individu atau kelompok yang menganut "absolutisme dalam pemahaman agama". Karakter tidak memiliki toleransi pada keyakinan yang berbeda, memaksakan pandangannya kepada orang lain, serta membenarkan kekerasan terhadap orang lain yang memiliki pemahaman keyakinan yang berbeda.

Kelompok yang melakukan tindakan kekerasan di luar batas-batas formal bisa dikategorikan sebagai kelompok vigilante yang tidak puas dengan sistem hukum dan negara. Kelompok tersebut berupaya menegakkan hukum sesuai dengan perspektif dan ideologi yang dianutnya. Rosenbaum \& Sederberg (1974) menyatakan secara umum vigilantism sebagai "taking the law into one's own hands." Menurut mereka vigilantisme berisikan tentang aksi-aksi atau tindakan-tindakan pemaksaan yang melanggar batas-batas hukum formal.

\footnotetext{
"It consists of acts or threats of coercion in violation of the formal boundaries of an established sociopolitical order which, however, are intended by the violators to defend that order from some form of subversion" (Rosenbaum \& Sederberg 1974:542).
}

Salah satu kelompok Islam militan yang muncul pasca rezim Soeharto tersebut adalah Front Pembela Islam (FPI). FPI didirikan pada tanggal 24 September 1998 oleh Misbahul Anam, salah satu kyai NU dan Habib Rizieq. Pada awalnya FPI dibentuk untuk menjadi basis massa pendukung bagi Partai Persatuan Pembangunan (PPP) dari kepemimpinan Hamzah Haz. Namun kehadiran Gerakan Pemuda Ka'bah membuat FPI gagal untuk menciptakan basis pendukung di luar Jakarta. Akhirnya FPI mendefinisikan ulang organisasinya sebagai gerakan anti imoralitas di Indonesia (Wilson 2006). Dalam perkembangannya, kelompok militan Islam ini sempat menjadi bagian dari kelompok Pamswakarsa yang didirikan oleh Jendral Wiranto dan Jendral Kivlan Zein untuk menghalau oposisi yang ingin menjatuhkan Presiden Habibie. Dengan ikatan yang dekat pada rezim tersebut, maka FPI dirumorkan cukup dekat dengan beberapa tokoh militer seperti Wiranto, Letnan Jenderal Djaya Suparman, serta Kapolri Noegroho Djajoesman (Wilson 2006). Setelah kelompok ini berdiri di 1998, FPI mampu mengumpulkan anggota lebih dari 100.000 orang yang tersebar di 26 provinsi (Abuza 2007, Wilson 2006).

Kelompok militan ini memiliki ideologi yang membantu mereka melegitimasi aksi kekerasan di masyarakat. Menurut Wilson (2006) Ideologi FPI terkait dengan dua tema besar. Pertama adalah pentingnya memasukkan Piagam Jakarta dalam konstitusi Indonesia. Piagam ini menekankan pada pengaplikasian hukum shari'a kepada semua masyarakat muslim. Berbeda dengan kelompok radikal lain seperti Laskar Jihad dan Hizbut Tahrir yang menginginkan berdirinya negara Islam, FPI masih menghargai demokrasi di Indonesia dan lebih memprioritaskan pada perbaikan moral bangsa melalui hukum islam. Seperti kutipan Rizieq bahwa "jika moral dan karakter tidak diubah maka tidak akan berguna untuk membicarakan mengenai perubahan di bidang ekonomi, masalah politik maupun hukum" (Abuza 2007:73). 
Selanjutnya, tema utama dari ideologi FPI adalah nilai Islam mengenai amar ma'ruf nahi munkar, memimpin manusia menuju kebajikan dan menjauhi kejahatan. Berdasar pada penegakan nilai keagamaan inilah tindakan-tindakan FPI terkadang berujung pada kekerasan. FPI percaya bahwa komunitas Islam di Indonesia telah diserang oleh ideologi barat dan imoral (Wilson 2006:284). Moralitas dalam pandangan FPI merupakan salah satu tanggung jawab yang diemban oleh pemerintah, tetapi pemerintah memiliki keterbatasan untuk mengaturnya. Di sinilah warga negara memiliki hak dan peran untuk melindungi komunitasnya meskipun dengan menggunakan kekerasan (Wilson 2006).

Seperti yang dinyatakan Rosenbaum \& Sederberg (1974) dalam tipologi kelompok vigilantisme, FPI bisa dikategorikan sebagai vigilantisme yang berbentuk kontrol terhadap kelompok sosial. Kekerasan dilakukan untuk melawan kelompok yang bertentangan dengan nilai yang dianutnya. Salah satu pemicu terjadi kontrol sosial melalui kekerasan adalah ketika nilai-nilai keagamaan terancam dengan penyebaran sekularisme atau kompetisi dengan keyakinan yang lain. Kontrol dengan kekerasan ini dianggap perlu diambil alih oleh pihak privat atau kelompok yang menamakan dirinya pengontrol moral ketika negara dianggap tidak hadir untuk mengendalikan masyarakat.

Semenjak organisasi ini berdiri, FPI selalu menggunakan aksi kekerasan untuk menekankan nilainilai yang dianutnya. Kemunculan FPI di ranah publik terjadi sebulan pasca kelompok ini didirikan. Kelompok tersebut menyerang aktivis mahasiswa dari Universitas Atmajaya, dengan dalih bahwa mahasiswa kristen merupakan bagian dari gerakan sayap kiri yang dibayar oleh Yahudi Amerika (Wilson 2006). Beberapa aksi lain tidak hanya menyerang pihak yang memiliki keyakinan yang berbeda tetapi juga pihak yang dianggap melanggar moral. FPI menganggap kelompok mereka sebagai pengendali moral di ranah publik dan merasa bahwa pemerintah tidak mampu menegakkan norma di masyarakat. Hal ini bisa dilihat dari aksi-aksi anarkis yang marak dilakukan FPI saat bulan ramadhan menjelang. Antara tahun 1999-2002 FPI melakukan sweeping dan penutupan tempattempat hiburan yang dianggap berkontribusi pada degradasi moral, seperti pub, karaoke, billiar, serta tempat hiburan malam lainnya (Wilson 2006). Tidak jarang aksi tersebut berujung pada pengrusakan dan kekerasan. Aksi kelompok ini mengingatkan pada aktivitas polisi agama Afganistan di bawah Taliban yang berpatroli keliling kota (Wahid 2009).

Aksi-aksi vigilantisme tersebut mendapatkan respon dari aparat kepolisian serta pemerintah untuk menegaskan bahwa FPI tidak kebal terhadap hukum. Seperti yang dikatakan Wilson (2006) Relasi antara polisi dan FPI semakin menegang pada tahun 2000-an. Pemimpin FPI, Rizieq sempat diamankan oleh polisi pada tahun 2001 pasca aksi demonstrasi penolakan invasi Amerika terhadap Afganistan. Setelah aksi ini Rizieq ditangkap oleh pihak kepolisian dengan alasan menyebar kebencian. Namun pimpinan FPI ini bisa lolos dari hukuman maksimal tujuh tahun menjadi tujuh bulan. Pada tahun 2003 tepatnya April-November Rizieq ditahan di rutan Salemba atas tindakan-tindakan anarkis yang pernah dilakukan, salah satunya beberapa tindakan pengrusakan di Jakarta. Pada tahun 2008, Rizieq dan 9 anggota FPI juga sempat ditahan karena menjadi tersangka dalam aksi kekerasan pada tanggal 1 Juni terhadap Aliansi Kebangsaan dan Kebebasan untuk Beragama dan Berkeyakinan (AKBB) di Monas (Kompas 2008). Aksi-aksi main hakim sendiri dan memaksakan kehendak ini sempat mendapat respon dari pemerintah. Pada tahun 2012 Kemendagri pernah mewacanakan pembekuan ormas ini karena meresahkan masyarakat. Namun, selang setahun kemudian Mendagri Gamawan Fauzi menarik kata-katanya kembali dan menganggap FPI sebagai salah satu aset bangsa dan meminta kepala daerah untuk bekerja sama dengan FPI sebagai ekspresi dari civil society (Kompas 2013).

\section{"Dayak bersatu menolak FPI"}

Penolakan terhadap FPI pernah terjadi di beberapa wilayah di Indonesia. Namun, aksi penolakan yang dilakukan oleh masyarakat Dayak di Kalimantan Tengah mampu mengekslusi kelompok militan Islam yang erat dengan main hakim sendiri (vigilantism) yang sering berujung pada kekerasan. Keberanian masyarakat Dayak ini mampu mengusir organisasi yang ingin didirikan di kawasan Kalimantan Tengah, yang dianggap tidak sesuai dengan nilai-nilai dan kebudayaan daerah 
setempat. Saya teringat pengalaman hadir dalam demonstrasi masyarakat Dayak untuk menolak pendirian FPI di Palangkaraya pada tanggal 11 Februari 2012. FPI selaku ormas Islam, yang memang sangat erat dengan tindakan kekerasan dan anarkis ini, berencana untuk mendirikan organisasinya di Palangkaraya dan ditolak langsung oleh masyarakat Dayak beserta lembaga adat.

Ada informasi yang diterima oleh masyarakat Dayak di Kalimantan Tengah para pimpinan FPI berencana datang ke Palangkaraya untuk memperingati hari besar Maulid Nabi dan pembukaan kantor cabang di Palangkaraya pada hari Sabtu 11 Februari 2012. Di dalam rombongan tersebut terdapat beberapa tokoh FPI pusat yaitu Muhsin Ahmad Alattas (Ketua Bidang Dakwah), Ahmad Sobri Lubis (Sekjen), K.H. Awit Masyhuri (Wasekjen) serta Maman Suryadi (Panglima LPI). Dikabarkan saat itu Habib Rizieq tidak ikut menghadiri acara karena sedang sakit (Tempo 2012).

Mendengar kabar bahwa akan ada peresmian FPI di Palangkaraya masyarakat Dayak yang juga didukung oleh lembaga adat, seperti DAD serta Gerakan Pemuda Dayak Indonesia Kalimantan Tengah (GPDI-KT) menolak kehadiran ormas Islam dengan melakukan aksi demonstrasi. Bundaran Besar Palangkaraya dipilih menjadi titik pusat aksi demonstrasi akan dilangsungkan. Sejak pagi, ratusan warga telah berkumpul di sekitar bundaran besar Palangkaraya. Massa semakin lama semakin memenuhi bundaran. Rombongan massa terus berdatangan dengan menggunakan motor maupun mobil bak terbuka dari beberapa daerah di Kalimantan Tengah seperti Pangkalanbun, serta Sampit.

Dalam aksi demonstrasi ini atribut-atribut yang dimaknai sebagai atribut perang bagi suku Dayak terlihat jelas. Sebagian besar memakai ikat kepala merah, yang menurut salah satu warga, merupakan simbol yang digunakan orang Dayak ketika pergi berperang. Sebagian orang tidak hanya menggunakan ikat kepala tetapi juga membawa senjata tajam berupa senjata khas suku Dayak, Mandau. Tidak hanya itu, terdengar secara bersahutan teriakan-teriakan warga yang berkumpul di bundaran serupa dengan teriakan dalam perang.

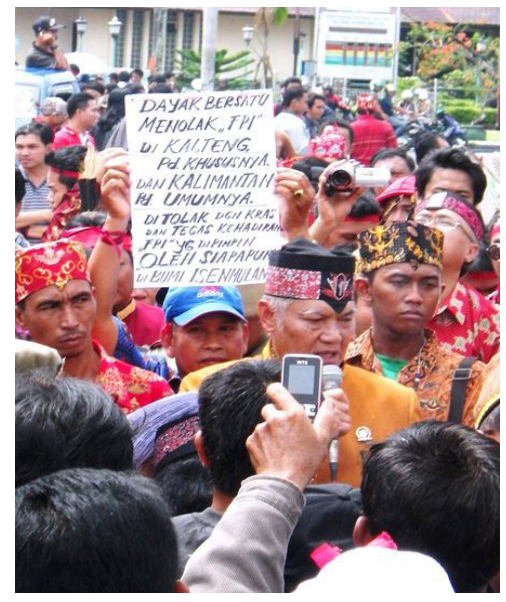

Gambar 1.

Lukas Tingkes (Wakil Ketua DAD) melakukan orasi penolakan FPI

saat aksi demonstrasi di Palangkaraya

(Sumber: Dokumentasi Pribadi)

Dalam aksi demonstrasi ini DAD beserta lembaga adat lainnya di Palangkaraya memiliki agenda untuk mendirikan organisasi tandingan untuk FPI. Lukas Tingkes selaku Wakil Ketua DAD membacakan orasi penolakan FPI karena dianggap ormas tersebut bisa meresahkan kehidupan masyarakat di Palangkaraya. Ormas yang menganggap dirinya sebagai 'polisi moral' ini identik dengan tindakan main hakim sendiri atau melakukan praktik vigilantisme. Selain itu, Lukas Tingkes juga membacakan ikrar pembentukan Barisan Pertahanan Masyarakat Adat Dayak (BPMAD). Organisasi ini dianggap mampu menjadi entitas yang bisa melindungi kehidupan masyarakat Dayak 
di Kalimantan Tengah. Dalam Perda No 16 tahun 2008 tentang Kelembagaan Ada Dayak, BPMAD merupakan sub-organisasi dari DAD yang memiliki tugas khusus untuk mengawal perjuangan masyarakat Dayak mempertahankan keberadaannya, membantu tugas Damang dalam menegakkan hukum adat dan mengantisipasi gangguan terhadap kedaulatan Negara Kesatuan Republik Indonesia di daerah perbatasan.

Pengukuhan organisasi itupun dilakukan di depan kerumunan masyarakat Dayak dari berbagai elemen yang telah berkumpul di Bundaran Besar Palangkaraya. Lukas Tingkes dengan suara lantang menyuarakan bahwa, "Kita masyarakat adat Dayak, pada hari ini tanggal 11 Februari 2012, [saya] Lukas Tingkes Wakil Dewan Adat Dayak, berdasarkan pada Undang-Undang 34 Perda 2008, mengukuhkan saudara menjadi anggota BPMAD." Kemudian disusul dengan pembacaan ikrar organisasi yang berisi:

\begin{abstract}
"BPMAD setia dan taat terhadap pancasila, UUD 1945, Bhinneka Tunggal Ika, dan Negara Kesatuan Republik Indonesia. BPMAD, menjunjung tinggi huma betang mempertahankan adat dan hak-hakmasyarakat Dayak, memperjuangkan peningkatan taraf hidup, ikut melakukan antisipasi dan mendukung aparat keamananan dan antisipasi keamanan di perbatasan serta mendukung damang adat".
\end{abstract}

BPMAD diharapkan menjadi satu-satunya organisasi yang dibentuk oleh masyarakat Dayak dengan tujuan turut mengamankan kawasan Palangkaraya. Dalam aksi tersebut Lukas Tingkes dengan lantang menegaskan bahwa untuk menjaga dan mengamankan lingkungan sosial Palangkaraya adalah orang Dayak dengan organisasi BPMAD. Diharapkan tidak ada organisasi lain yang ikut campur dalam mengamankan kawasan Palangkaraya selain orang Dayak melalui badan atau organisasi tersebut. Dalam rapat setelah deklarasi ini, Tingkes juga menyatakan bahwa BPMAD akan mengawasi munculnya kelompok garis keras di Palangkaraya. "Kami menolak tegas kelompok itu supaya masyarakat bisa hidup damai dan kerukunan beragama terjaga" (Kompas 2012).

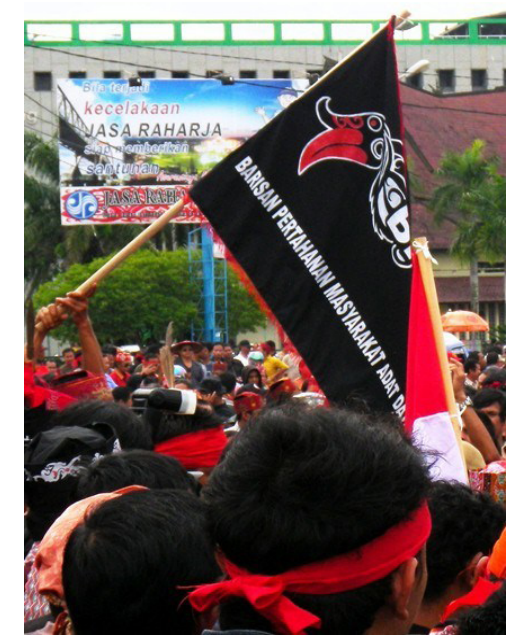

Gambar 2.

Bendera BPMAD yang dikibarkan salah satu pengunjuk rasa (Sumber: Dokumentasi Penulis)

Aksi demonstasi tersebut tidak hanya berhenti pada pengukuhan organisasi tandingan untuk mengusir FPI, bahkan warga Dayak sampai menerobos bandara palangkaraya untuk mencegah datangnya pengurus FPI. Sebagian warga Dayak yang sempat terkonsentrasi di bundaran mulai berkonvoi menuju bandara Palangkaraya untuk menghalangi pengurus FPI menginjakkan kaki di Palangkaraya. Sesampai di bandara, warga berhasil masuk dan mengepung sampai landasan terbang dimana pesawat yang ditumpangi oleh pendiri FPI tersebut. Melihat keadaan tersebut, agar tidak 
terjadi insiden, Kasatlantas, Kepala Keamanan Bandara, dan kru pilot Sriwijaya, menerbangkan kembali pesawat ke Banjarmasin (Tempo 2012).

Meskipun berhasil mengusir pengurus pusat FPI dari Palangkaraya, warga masih meneruskan aksinya menuju salah satu rumah anggota FPI. Rumah anggota tersebut didatangi oleh warga yang baru saja melakukan aksi dari bundaran dan bandara. Warga Dayak yang berada di rumah tersebut melakukan pengrusakan dengan memecahkan kaca jendela dengan lemparan benda keras. Selain itu warga juga sempat membakar tenda yang berada di halaman rumah tersebut. Tidak ada korban dalam aksi tersebut, namun beberapa kelompok Islam yang tergabung dalam Gerakan Umat Islam Bersatu (GUIB) meminta pihak yang melakukan pengrusakan harus bertanggung jawab (voa-islam 2012).

Menanggapi aksi demonstrasi masyarakat Dayak serta lembaga adat di Palangkaraya, diadakan pertemuan untuk menghasilkan pernyataan sikap tentang penolakan FPI. Rapat dilakukan pada Senin, 13 Februari 2012 di Aula Jayang Tingang dihadiri oleh pimpinan agama, pimpinan organisasi masyarakat serta Forum Koordinasi Pimpinan Daerah Kalteng. Dari pernyataan yang dibuat pada pertemuan tersebut disebutkan bahwa penolakan FPI tidak ada hubungannya dengan isu agama dan suku. Kemudian meminta agar semua pihak untuk bersama-sama menjaga kerukunan umat beragama (Antara 2012).

Gerakan yang dilakukan oleh masyarakat Dayak di Palangkaraya yang berhasil mengekslusi FPI memberikan inspirasi terhadap gerakan penolakan lain. Tidak berselang lama dari aksi di Palangkaraya, tercetus aksi lain dari komunitas yang menamakan dirinya komunitas anti kekerasan dengan bertajuk "Indonesia tanpa FPI". Aksi ini berawal dari inspirasi penolakan terbuka masyarakat Dayak. Melalui interaksi media sosial akhirnya aksi ini dilakukan dengan tujuan mengkritik negara yang tidak pernah mengusut tuntas aksi kekerasan yang pernah dilakukan oleh kelompok tertentu (BBC 2012).

\section{Simpulan}

Pertemuan dua entitas yang sama-sama ingin menuntut hak dan menunjukkan politik perbedaan berujung pada kontestasi. Identitas Islam yang diwakili oleh organisasi FPI menginginkan adanya perubahan dalam moral bangsa yang dianggap sudah terdegradasi. Di sisi lain, Masyarakat Dayak setelah pasca reformasi selalu berjuang untuk mendapatkan porsinya di Kalimantan Tengah terkait dengan sumber daya dan kekuatan politik. Penolakan FPI oleh Masyarakat Dayak di Palangkaraya memberikan gambaran bahwa meskipun tiap kelompok memiliki identitas yang berbeda tetapi ketika bertemu pada konteks tertentu akan terjadi ekslusi ketika salah satu pihak tidak bisa menghargai perbedaan.

Bayang-bayang vigilantisme menjadi salah satu hal yang memicu masyarakat Dayak melakukan aksi demonstrasi melawan FPI. Kekerasan yang selalu mewarnai aksinya sebagai 'polisi moral' membuat FPI menjadi momok kelompok yang selalu membuat keresahan bagi masyarakat yang dianggap memiliki nilai-nilai yang berbeda. Untuk menghindari kemungkinan aksi vigilantisme yang dilakukan FPI, Dewan Adat Dayak memprakarsai pembentukan organisasi tandingan yaitu BPMAD. Organisasi turunan dari DAD ini dianggap mampu menjaga kedaulatan di Kalimantan Tengah dan mengontrol kemungkinan munculnya kelompok garis keras di wilayahnya. Bentuk penolakan ini juga memberikan pengaruh kepada bentuk-bentuk penolakan lain di Indonesia. Penolakan terbuka oleh Masyarakat Dayak menjadi contoh dari gerakan lain seperti "Indonesia tanpa FPI" yang digelar beberapa saat setelah kejadian di Palangkaraya. Kesadaran bahwa kelompok masyarakat mampu menegosiasikan posisinya untuk menolak kehadiran sebuah kelompok yang membawa ideologi tertentu menjadi poin penting dari kasus ini. Bahwa tindakan vigilantisme atas nama agama tidak bisa dilanggengkan, karena menodai hak kelompok lain yang berbeda. Jika angan-angan masyarakat yang multikultural berdasarkan penghargaan pada perbedaan yang dimiliki oleh kelompok tidak dilakukan, maka gerakangerakan perlawanan atau penolakan bisa terjadi antara satu kelompok kepada kelompok yang lain. Aksi ini dilakukan karena tiap kelompok bisa menuntut hak politik perbedaannya sesuai dengan klaim-klaim keunikan kualitas, kontribusi, dan sejarah kelompok tersebut. 


\section{Daftar Pustaka}

Abuza Z (2007) Political Islam and Violence In Indonesia. New York: Routledge.

Antara (2012) Lima pernyataan sikap terhadap penolakan fpi. [Diakses 13 Juni 2016]. http://www. antarajateng.com/detail/-lima-pernyataan-sikap-terhadap-penolakan-fpi.html.

BBC (2012) Aksi unjuk rasa Indonesia tanpa FPI di Jakarta. [Diakses pada 13 Juni 2016]. http:// www.bbc.com/indonesia/berita_indonesia/2012/02/120214_antifpi.shtml.

Benda-Beckmann F \& Benda-Beckmann K (2011) Myths and stereotypes about adat law: A reassessment of Van Vollenhoven in the light of current struggles over adat law in Indonesia. Bijdragen tot de Taal-, Land- en Volkenkunde 167 (2/3):167-195.

Davidson \& Henley (eds) (2007) The Revival of Tradition in Indonesian Politics: The Deployment of Adat from Colonialism to Indigenism. New York: Routledge.

Diansyah A (20110 Eksistensi damang sebagai hakim perdamaian adat pada masyarakat Suku Dayak di Palangkaraya. Tesis, Universitas Udayana, Bali (tidak diterbitkan).

Denzin NK \& Lincoln YS (2005) Introduction: The Dicipline and Practice of Qualitative Research. Dalam: NK Denzin \& YS Lincoln (ed). The Sage Handbook of Qualitative Research Third Edition. California: Sage Publications.

Holston J \& Appadurai A (1996) Cities and citizenship. Public Culture (8):187-204.

Holton J (2008) Insurgent Citizenship: Disjunctions of Democracy and Modernity in Brazil. New Jersey: Princeton University Press.

Kompas (2008) Habib Rizieq 12 Jam Tanpa Surat Penahanan. [Diakses 13 Juni 2016]. http://lipsus. kompas.com/grammyawards/read/2008/08/20/22311928/Habib.Rizieq.12.Jam.Tanpa.Surat. Penahanan.

Kompas (2013) Mendagri: FPI adalah Aset Bangsa. [Diakses pada 13 Juni 2016] dari http://nasional. kompas.com/read/2013/10/24/1757390/Mendagri.FPI.adalah.Aset.Bangsa.

Klinken Gerry Van (2001) Indonesia's New Ethnic Elites. Dalam Workshop Indonesia in Transition, Yogyakarta, 22 Agustus 2001. [Diakses pada 14 Mei 2016]. http://ssrn.com/abstract=1127117

Klinken Gerry Van (2007) Perang Kota Kecil: Kekerasan Komunal dan Demokratisasi di Indonesia (terjemahan). Jakarta : Yayasan Obor Indonesia.

Kymlicka W (1995) Multicultural Citizenship: A Liberal Theory of Minority Rights. New York: Oxford University Press.

Peraturan Daerah Propinsi Daerah Tingkat I Kalimantan Tengah Nomor 14 Tahun 1998 tentang Kademangan di Propinsi Daerah Tingkat I Kalimantan Tengah.

Peraturan Daerah No.18 tahun 2008 mengenai Kelembagaan Adat Dayak di Kalimantan Tengah.

Rosenbaum HJ \& Sederberg PC (1974) Vigilantism: An analysis of establishment violence. Comparative Politics 6(4):541-570.

Tempo (2012) Kronologi penolakan FPI Kalimantan Tengah. [Diakses 13 Juni 2016]. https://m. tempo.co/read/news/2012/02/14/078383860/kronologi-penolakan-fpi-kalimantan-tengah.

Wahid A (ed) (2009) Pengantar Editor. Dalam Ilusi Negara Islam: Ekspansi Gerakan Islam Transnasional di Indonesia. Jakarta: The Wahid Institute. Diunduh pada http://libgen.io/ads.ph p?md5=FBC80CC8EE88E31F2EAB7619B7B0E062.

Voa-Islam (2012) MUI, NU dan Muhammadiyah Kecam Perusakan Rumah Anggota FPI. [Diakses 13 Juni 2016]. http://www.voa-islam.com/read/indonesiana/2012/02/15/17744/muinumuhammadiyah-kecam-perusakan-rumah-anggota-fpi-palangkaraya/\#sthash.rnuBavM6. dpuf.

Wilson ID (2006) Continuity and change the changing contours of organized violence in post-new order Indonesia. Critical Asian Studies 38:2:265-297. 